Military Technical College

Kobry El-Kobba

Cairo, Egypt

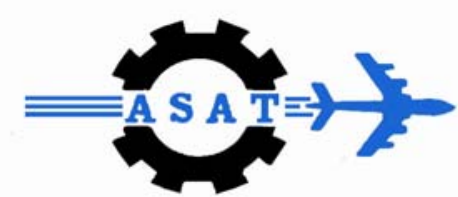

12-th International Conference on Aerospace Sciences \& Aviation Technology

\title{
DEVELOPMENT OF AN ORIGINAL PROCESS FOR THE PRELIMINARY DESIGN OF AN UAV SYSTEM BASED ON MULTIPLE MODULES
}

\author{
TARIQ H.ELSONN*, MOKHTAR AL-NOMROSSI**, HANI M.NEGM+, \\ and MOHAMED E. MANSOUR++
}

\begin{abstract}
The research work presented here is apart of an on-going program in the development of Unmanned Aerial Vehicle system, at the conceptual and preliminary design levels, in Aerospace Research Center (ARC-Egypt). The main objective is the implementation of the developed design process in MDO software for UAV design development. It is applied to the previously proven SAHM UAV platform. A model with a specified design variables has been chosen, while the design constraints are selected to cover the entire UAV modules; geometry, aerodynamic, performance, stability, weight and structure. The design objective is to minimize the air vehicle ground launch weight. The optimization method is the steepest descent with an exterior penalty operator. Results obtained show that all design disciplines are quite matched within the requirements. Generated version of SAHM UAV shows a significant reduction of about $11 \%$ in the ground launch weight relative to the baseline design. Modal testing was performed on both the wing and the whole airframe of the SAHM UAV. Natural frequencies, and mode shapes were identified. At the same a detailed FE model of the wing was developed on MSC/NASTRAN. One-way ANOVA has been implemented for the compatibility of the numerical and experimental results, which correlates well.
\end{abstract}

KEY WORDS: Unmanned Aerial Vehicle, Preliminary Design, Multidisciplinary Design Optimization, Gradient Method, Penalty Method, and Modal Test.

*PhD student, Dpt. of Mech Eng. Aeronautics, Karary Academy of Technology, Khartoum - Sudan. Email: Int273@yahoo.com.

** Professor, Aerospace Research Center, (ARC-Egypt).

+ Professor, Dpt. Of Aeronautical Eng., Cairo University, Guiza, Egypt.

++Associate professor, Dpt. of Mech Eng. Karary Academy of Technology, Khartoum Sudan. 


\section{NOMENCLATURE}

\begin{tabular}{|c|c|}
\hline $\begin{array}{l}a \\
b_{v}\end{array}$ & $\begin{array}{l}\text { Number of treatments } \\
\text { Vertical tail span }(\mathrm{ft})\end{array}$ \\
\hline$b_{w}$ & Wing span (ft) \\
\hline$C_{N}^{\beta}$ & Yawing moment due to sideslip (per degree) \\
\hline$c r_{V}$ & Vertical tail root chord (ft) \\
\hline$c t_{V}$ & Vertical tail tip chord (ft) \\
\hline$c r_{W}$ & Wing root chord (ft) \\
\hline$c t_{w}$ & Wing tip chord (ft) \\
\hline $\begin{array}{l}D_{f} \\
E\end{array}$ & $\begin{array}{l}\text { Fuselage Diameter (ft) } \\
\text { Endurance (hr) }\end{array}$ \\
\hline$\vec{g}$ & Inequality constraint vector \\
\hline $\mathrm{H}_{0}$ & Null hypothesis \\
\hline $\mathrm{H}_{1}$ & Alternative hypothesis \\
\hline $\mathrm{L}_{\mathrm{f}}$ & Fuselage Length (ft) \\
\hline $\mathrm{n}$ & number of replicates \\
\hline $\mathrm{R}$ & Range, Random test, Regression coefficient \\
\hline S & Sine test \\
\hline$t_{d}$ & Width of wing box beam ( $\mathrm{ft}$ ) \\
\hline$t_{h}$ & Height of wing box beam (ft) \\
\hline$V_{\text {crui }}$ & Cruise speed (km/hr) \\
\hline$W_{f e q}$ & Fixed equipment weight (lb) \\
\hline$W_{\text {fuel }}$ & Fuel weight (lb) \\
\hline$W_{\text {payload }}$ & Payload weight (lb) \\
\hline$W_{p w p}$ & Power plant weight (lb) \\
\hline$W_{s t r}$ & Structure weight (lb) \\
\hline$W_{t f o}$ & Trapped fuel and oil weight (lb) \\
\hline$\vec{x}$ & Design variable vector \\
\hline
\end{tabular}

\section{Greek Letters}

$\Lambda_{w_{C} / 4}$

$\Lambda_{v_{C} / 4}$

$\sigma$
Wing Sweep angle at quarter chord (deg)

V.T Sweep angle at quarter chord (deg)

Bending stress (Mpa) 
$\tau$

\section{Abbreviations}

$\begin{array}{ll}\text { ARC } & \text { Aerospace Research Center } \\ \text { Ceilalt } & \text { Ceiling altitude (ft) } \\ \text { df } & \text { Degree of freedom } \\ \text { D.V } & \text { Design variable } \\ \text { FRF } & \text { Frequency response function } \\ \text { GLW } & \text { Ground launch weight (lb) } \\ \text { MDO } & \text { Multidisciplinary Design Optimization } \\ \text { MS } & \text { Mean square } \\ \text { RFP } & \text { Request for proposal } \\ \text { ROC } & \text { Rate of climb (ft/min) } \\ \text { SS } & \text { Sum of squares } \\ \text { SM } & \text { Static margin } \\ \text { TTC } & \text { Time to climb (sec) } \\ \text { UAV } & \text { Unmanned Aerial Vehicle } \\ \text { VT } & \text { Vertical tail }\end{array}$

\section{INTRODUCTION}

Due to their current successes, Unmanned Aerial Vehicles (UAV's) are becoming attractive field of research and development for a variety of actual and potential applications. UAV's are growing in interest because of the diverse missions they can accomplish without the risk of human life [1], and [2].

Unmanned air vehicle are required to be light weight, low power, and small in size. These parameters become the limiting factors in the sizing of the unmanned air vehicle. Advanced technology in the areas of miniaturized flight controls, sensors, communications and advanced materials support the reduction in size, weight and cost of the UAV system. Lightweight UAV design creates several unique stability challenges. Obtaining a stable image requires an actively stabilized air vehicle. Therefore, the inherent dynamic characteristics are required to be identified in order to maintain steady flight in extremely turbulent conditions.

With these considerations in mind, a considerable progress has to be made in analyzing such problems and trying to achieve the above goals. The critical challenge of providing designers with a reliable, efficient and general tool for capturing crucial full vehicle information early in the design cycle remains unsatisfied. These facts represent the actual motivation for the present work.

At the current time, in order to follow this trend, new generations of SAHM UAV are under development as part of the Aerospace Research Center, (ARC-Egypt,) programs for a reconnaissance, surveillance, and electronic warfare missions. An extensive effort have been undertaken to analyze these programs. The challenge of successful and 
accurate design is to integrate both the theoretical and experimenttal activities during the development procedures, based on substantial literature of previous and already proven platforms. The successful design of a UAV relies on the tight integration of a variety of aeronautical engineering disciplines.

Today, the aircraft design community no longer seeks the best aerodynamic or the best structural solutions, but rather the optimal overall solution, in what is called multidisciplinary optimization (MDO) [3]. The use of MDO in conceptual and preliminary design phases of development a UAV system provides the designer with better insight into the coupled nature of different disciplines related to design [4].

This paper describes a developed process for the design of UAV with disciplines specific analyses. The process considers a simultaneous optimization of the vehicle design modules using MDO formulation. Specifically, this paper describes how the MDO formulation and analysis tools are employed. Finally, present the optimization results and the computational effort required to solve the problem are presented.

\section{MDO PROBLEM STATEMENT AND FORMULATION}

The objective of this optimization study is to determine the UAV configuration that will meet specified constraints and minimize the ground launch weight (GLW) of the UAV. An integrated MDO methodology is developed and applied where the UAV disciplines are included in the methodology.

\section{Objective Function}

The UAV MDO program has been developed to accommodate a combination of objective functions. Of most interest in this study is the ground launch weight (GLW).

\section{Design Variables}

To perform the numerical optimization of the UAV configuration, the latter has to be completely and uniquely described by a set of design variables, which are fully independent.

\section{Constraints}

The constraints imposed an the UAV MDO program setup fall into three categories: geometrical constraints (side constraints), physical constraints, and constraints implicit in the analysis. The implicit constraints are not handled by the optimization program, but rather are part of the analysis or geometry.

\section{Normalization of Design Variables and Constraints}


All the design variables and the constraints are normalized before being input into the optimizer. This procedure is important in the optimization process so that they are of the same order of magnitude.

\section{SAHM UAV Description and Mission Profile}

In this study, a baseline UAV design is used to provide a point near the interior of the feasible design domain. The baseline geometry is from the SAHM UAV configuration designed at Aerospace Research Center (ARC-Egypt).

The SAHM UAV is a monoplane delta-wing air vehicle that provides a complete airframe performance in all configurations and flight conditions. The high level of integration between the wing, fuselage, vertical tail, and control surfaces inherent in its design, allows it to take advantage of the synergistic nature between the different aircraft design disciplines, hence resulting in an aircraft with better performance than a conventional design. The aircraft powered by a pusher engine and built from typical aerospace Eglass polyester composite material. The aircraft is usually lunched, and can cruise at speed of $(300 \mathrm{~km} / \mathrm{hr})$, and has a maximum altitude of $(3 \mathrm{~km})$. It can operate for about 3 hours and has an operational range of about $(100 \mathrm{~km})$. With this concept of design, MDO will be used to identify the advantages of this integration and highlight its benefits.

The mission requirement is the set of conditions according to which the aircraft must be designed. A typical mission profile is given in Fig. 1, while the mission performance requirements is shown in table 1.

Table 1 Mission performance requirements

\begin{tabular}{|l|l|}
\hline Item & Requirements \\
\hline payload & $30 \mathrm{~kg}$ \\
\hline Max Mach \# & 0.1 \\
\hline Fuel & JET A1,(Benzene) \\
\hline Engine Type & $\begin{array}{l}\text { Single, piston - } \\
\text { propeller/pusher (35) hp }\end{array}$ \\
\hline
\end{tabular}

\section{The SAHM UAV Optimization Problem}

The SAHM UAV design employs 12-design variables and 20- nonlinear inequality constraints, which consist of geometric, aerodynamic, weight, performance, stability, and structure. The design problem was examined to further develop the MDO methodology. The variables for this design problem are listed in Eqs. (4-8), while the constraints are those presented in Eqs. (9-14). 
For this optimization problem, the gross launch weight (GLW) is formulated as a nonlinear constrained optimization function. In formal optimization terms this problem may be expressed as:

Minimize $G L W(x)$,

Subjected to: $\quad g_{i}(x) \leq 0, i=1, \ldots, 20$

$$
\begin{array}{r}
x_{\text {lower }} \leq x \leq x_{\text {upper }} \\
\mathrm{x}=\left[\begin{array}{llll}
\mathrm{x}_{1}, & \mathrm{x}_{2}, & \ldots . . . & \mathrm{x}_{\mathrm{n}}
\end{array}\right]
\end{array}
$$

where $\mathrm{x}$ is a vector of $n_{v}=12$ design variables, $x_{\text {lower }}$ is the vector of the lower bounds in the design variables, $x_{\text {upper }}$ is the vector of the upper bounds in the design variables, and $g(x)$ is the vector of $n_{g}=20$, nonlinear inequality constraints.

$$
g_{i}=\left[\begin{array}{lllll}
g_{1}, & g_{1}, & \cdot & \cdot & g_{n}
\end{array}\right]
$$

The Design variables used in the UAV MDO program are as follows:

$x=$ vector of design variables

$$
\begin{gathered}
x=\left[\begin{array}{c}
x_{w} \\
x_{\text {fus }} \\
x_{V . T} \\
x_{W . B}
\end{array}\right]=\left\{\begin{array}{c}
\text { Wing design variables } \\
\text { Fuselage design variables } \\
\text { V.T design variables } \\
\text { WingBox design variables }
\end{array}\right\} \\
x_{W}=\left[\begin{array}{c}
b_{w} \\
\Lambda_{w c / 4} \\
c r_{w} \\
c t_{w}
\end{array}\right]=\left\{\begin{array}{c}
\text { Wing span } \\
\text { wing quarter chord sweep angle } \\
\text { wing root chord } \\
\text { wing tip chord }
\end{array}\right\} \\
{ }^{\text {fus }}=\left[\begin{array}{c}
D_{f} \\
L_{f}
\end{array}\right]=\left\{\begin{array}{c}
\text { fuselage diameter } \\
\text { fuselage length }
\end{array}\right\}
\end{gathered}
$$




$$
\begin{gathered}
X_{V . T}=\left[\begin{array}{c}
b_{v} \\
\Lambda_{v c / 4} \\
c r_{V} \\
c t_{V}
\end{array}\right]=\left\{\begin{array}{c}
\text { V.T span } \\
\text { V.T quartet chord sweep angle } \\
\text { V.T root chord } \\
\text { V.T tip chord }
\end{array}\right\} \\
X_{W . B}=\left[\begin{array}{c}
t_{d} \\
t_{h}
\end{array}\right]=\left\{\begin{array}{c}
\text { wingbox skin thickness } \\
\text { wingbox spar web thickness }
\end{array}\right\}
\end{gathered}
$$

The geometric constraints are applied to the SAHM UAV configuration to prevent the optimizer from creating grossly unrealistic designs. The stability and performance constraints are considerably more computationally expensive than the others. The constraints are written as:

$$
l \leq\left(\begin{array}{c}
\operatorname{Geom}(x) \\
\operatorname{Aero}(x) \\
\operatorname{Perform}(x) \\
\operatorname{Stab}(x) \\
\operatorname{Struct}(x)
\end{array}\right) \leq u
$$

$$
\operatorname{Geom}(x)=[x]=\{\text { Geometric design variables }\}
$$

$$
\operatorname{Aero}(x)=\left[V_{\text {crui }}\right]=\{\text { cruise velocity }\}
$$

$$
\operatorname{Perfor}(x)=\left[\begin{array}{c}
E \\
R \\
R O C \\
T T C \\
\text { Ceilalt }
\end{array}\right]=\left\{\begin{array}{c}
\text { endurance } \\
\text { range } \\
\text { rate of climb } \\
\text { time to climb } \\
\text { ceiling altitude }
\end{array}\right\}
$$

$$
\begin{array}{r}
\operatorname{Stab}(x)=\left[\begin{array}{c}
\mathrm{S} . \mathrm{M} \\
\beta \\
C N
\end{array}\right]=\left\{\begin{array}{c}
\text { static longitudinal stability } \\
\text { static lateral stability }
\end{array}\right\} \\
\operatorname{Strcut}(x)=\left[\begin{array}{c}
\sigma \\
\tau
\end{array}\right]=\left\{\begin{array}{c}
\text { wing bending stress } \\
\text { wing shear stress }
\end{array}\right\}
\end{array}
$$


where $I$ and $u$ are the lower and upper bounds respectively, andGeom $(x)$, $\operatorname{Aero}(x), \operatorname{Perfor}(x), \operatorname{Stab}(x)$, and Strcut $(x)$ are the geometric, aerodynamic, performance, stability, and structure constraints respectively.

The weight equations for the UAV's-type platforms are not available in literature, so using equations presented in [5 ], for a general aviation aircraft, is an attempt to estimate the component weights.

Based on this, the GLW is defined as:

$$
G L W=W_{\text {str }}+W_{p w p}+W_{\text {feq }}+W_{\text {tfo }}+W_{\text {fuel }}+W_{\text {payload }}
$$

Where:

$$
W_{\text {str }}=\text { wing weight }+ \text { fuselage weight }+ \text { vertical tail weight }
$$

\section{METHODOLOGY}

To solve this problem, a gradient-based optimization algorithm was developed, coupled with a parameterized modules system of the vehicle analysis. The specific algorithm used to implement the specified problem was the steepest descent with penalty function method.

\section{Optimization Based on Gradient Methods}

Gradient-based optimization algorithms are a class of search methods for real-valued functions. For the non-linear optimization problem, the constraints can be represented by penalty functions that treat the constraints. The penalty function is added (for a minimization problem) to overall objective function. In this way the objective function is "penalized" for being outside the feasible region, and gradient methods will lead the design away from the penalties and toward a feasible solution. Gradient methods use the gradient of the objective function [6]. For the gradient -based optimization methods, the search direction is determined using first derivatives of the objective function and constraints with respect to the vector of design variables. Further detail concerning these methods can be found in [7], [8], and [9].

\section{Modules Analysis}

This section discusses the analysis of aircraft analysis modules used for this study. These modules are needed to ensure feasible aircraft performance and configuration estimates. 


\section{Geometry module}

This module calculates the surface areas; sweep angles based on the based line values, and clarify the layout of the aircraft and some of the referenced dimensions. These depend on the requirements of the wing planform, vertical tail, and fuselage shape. Calculations used in this module based on relation obtained from [5] and [10].

\section{Aerodynamic module}

The aerodynamics module calculates the cruise velocity, the lift, and then estimates the drag polar of the UAV assuming parabolic drag polar. The module models the zero-lift drag, and the induced drag of the UAV. The theories behind these types of drag are presented in [5], [10] and [11].

\section{Weight module}

The purpose of the weights module is to assign initial values of weights for computation. The estimated ground launch weight must be entered as the starting values for converging the aircraft to the proper weight. Known weights can also be specified as fixed, non-varying weights. The structural weight was represented by the weights of the wing, fuselage, and vertical tail. These weights were determined from the component geometries. The empty weight fraction was multiplied by (0.95) to account for the composites [5]. Statistical and empirical methods are used for determining each of the SAHM UAV component weights. Currently only a general aviation aircraft class method for the wing, vertical, and fuselage weights estimation is used. The method and the equations for weight computation is discussed in [5], and [10].

\section{Structure module}

This module deals with the wing weight that was obtained from weight module. This module takes into account the geometry of the wing sections which is modeled as a wing-box structure. The wing box structure considered here is made up of two spars (front and rear), with upper, and lower skins. All components are made of E-glass. Both spars are assumed to be of the same thickness and the upper and lower skins as well. The wing structural design variables consist of the thickness of the upper and lower skins $\left(t_{d}\right)$, and the thickness of the spar webs $\left(t_{h}\right)$. Only stresses at root section are applied as the structural constraints.

The box beam structure is then defined using the following assumptions:

1. The whole lift is taken by the box beam structure.

2. The lift acts on the centroid of the wing planform.

3. The wing weight is uniformly distributed along the planform.

4. The wing structure is a cantilever and the material is uniformly distributed along the root airfoil contour.

\section{Performance module}


This module is responsible for calculating the aircraft cruise performance, where the UAV range, endurance, rate of climb, time to climb and ceiling altitude are calculated. Range and endurance are calculated based on the Breguet equations, while the other parameters are calculated based on relations estimated by [5] and [11].

\section{Stability module}

Only the static longitudinal and lateral stabilities are considered in the MDO formulation. The analysis comprises the static margin and the yawing moment due to sideslip. A key theory in describing and analyzing the stability module is found in [10], and [11].These design conditions are enforced in the MDO framework via the use of optimization inequality constraints.

\section{OPTIMIZATION PROCEDURE}

The design problem under consideration consists of performing an integrated optimization of most of the modules which makeup the aircraft overall system. Thus, the optimization technique described in the previous section will be adopted in the context of designing an optimal Unmanned Aerial Vehicle (UAV) configuration. Once the various modules have been constructed it is essential to facilitate flow of data amongst them and to link them with the optimization algorithm.

The following steps outline the optimization procedure:

1. Initialize all the design variables and constraints and perform analysis.

2. Once the objective function and constraints are evaluated, the data is passed onto the optimizer, which evaluates their gradient and moves in the direction that minimizes the objective function while satisfying the constraints.

3. If convergent exist, stop, and else go to step one.

\section{MODAL TESTING}

\section{Test Objective}

The main objective of this test is to extract the dynamic characteristics (natural frequency and mode shapes) of the test articles.

\section{Test Plan}

The modal testing is performed on two test articles; SAHM UAV wing only, which considered 37-measurement locations on the wing, and the SAHM UAV as a whole, which comprised 45 measurement locations all over the airframe. This test gives a detailed look at the global modes of the UAV. Figures (2) and (3) show the measurement locations on both test articles.

\section{SAHM UAV DESCRIPTION}

The description of the vehicle used for this test was given in a previous section 


\section{Test Setup}

\section{Test equipment}

The equipment used in this experiment is common to both methods of excitation. It includes; Kistler force sensor 9712B500 (to measure excitation force), electrodynamic exciter ET-139 (to excite the structure), power amplifier PA-138-1(to drive the exciter), accelerometer calibrator 28959FV (to calibrate the accelerometers), wave form generator 33120A (to calibrate force sensor), kistler accelerometers 8776M03(to measure response points), and LMS DIFA III system.

\section{LMS DIFA III system}

The LMS DIFA III system acts as a source of excitation signal, and data acquisition system through which response channels; accelerometers measurements; are measured. The LMS DIFA III system is shown in Figure (4).

\section{Test procedures}

One of the critical tasks was to suspend the test objects. As it is known, the method of structure support during vibration testing plays an important role in the determination of the modal characteristics of the structure .In the first test, the wing was fixed to a rigid stand to be in a flight-like configuration, while in the second test, in order to simulate a free-free condition, the SAHM UAV was softly suspended using air-cables attached to airframe at the center-of- gravity location of the whole air vehicle, see figure (5). The structural design of SAHM limited the locations available for suspension of the airframe to those where the parachute is attached to the fuselage bulkheads).

The wing structure is excited by two vertical shakers securely attached to its tips. Thirtyseven accelerometers are attached to the wing on its upper surface. The measuring cables are connected to corresponding channels in LMS DIFA III system. The whole frame of the UAV was excited at three different locations as follows:

i. Two exciters attached vertically to wing tips.

ii. Single exciter attached vertically to fuselage nose-cone at the bottom.

iii. Single exciter attached horizontally to the vertical tail, left side.

The modal testing procedure for the entire airframe required some additional steps. The accelerometers have to be kept parallel to the SAHM reference axis. It should be noted that the accelerometers had to be rotated while measuring the responses on the side of the fuselage and vertical tail. Modal data was taken from 45 measurement locations covered the entire airframe of the UAV, using lightweight accelerometers.

\section{Excitation method}

The choice of an excitation method is critical to successful performance of a modal test. Excitation techniques are discussed in many publications, [12] and [13]. Random excitation and sine sweep excitation techniques will be used within this experiment.

At first, the wing was randomly excited over a frequency range of 0 to $200 \mathrm{~Hz}$. Data were acquired at each of the 37 locations. Twenty averages were used to calculate each frequency response function. A total of ten random tests were conducted on the wing. Secondly, the wing was excited by the sine-stepped technique, within frequency sweeps 
excitation over a range of 0 to $100 \mathrm{~Hz}$. Two averages were used to calculate each frequency response function, (FRF). Once data acquisition was completed for the entire wing, frequencies were estimated for each mode. A total of six sine tests were performed on the wing.

During exciting the whole frame of the SAHM UAV, the same methods of excitation discussed previously were applied for each of the three situations stated above, but with the following considerations:

a. Ten random tests at frequency range of 0 to $200 \mathrm{~Hz}$.

b. Ten sine tests at frequency range of 0 to $50 \mathrm{~Hz}$

c. Ten sine tests at frequency range of 50 to $100 \mathrm{~Hz}$.

A number of tests were conducted. Thirty tests were conducted for each of the threeexcitation locations of the airframe. (A total of ninety tests). During testing, the coherence function was continually monitored. (Coherence is a measure of the quality of the output with respect to the input).

\section{RESULTS AND DISCUSSION}

\section{Optimization Results}

Figure 6 Shows the convergence history of all design variables for the SAHM UAV configuration during the optimization, while table (2) summarizes the initial and optimal values of the design variables, and objective function. The optimum design of the SHM UAV has $11.3 \%$ lighter GLW versus the original design.

Table.2. Optimization results versus the base-line configuration

\begin{tabular}{|c|c|c|c|c|c|c|c|}
\hline No. & Variable & initial & final & No. & D.V & initial & final \\
\hline 1 & $b_{w}$ & 6 & 7.1 & 7 & $b_{V}$ & 2.4 & 2.8 \\
\hline 2 & $\Lambda_{W_{C} / 4}$ & 30 & 29.19 & 8 & $\Lambda_{V_{C} / 4}$ & 33 & 35 \\
\hline 3 & $c r_{W}$ & 4 & 4.92 & 9 & $c r_{V}$ & 1.8 & 2.01 \\
\hline 4 & $c t_{w}$ & 2 & 1.49 & 10 & $c t_{V}$ & 0.6 & 0.73 \\
\hline 5 & $D_{f}$ & 1.5 & 0.87 & 11 & $t_{d}$ & 0.010 & 0.013 \\
\hline 6 & $L_{f}$ & 9 & 6.59 & 12 & $t_{h}$ & 0.02 & 0.013 \\
\hline & & Initial & Final & Reduction & & & \\
\hline & GLW & 258.5 & 229.3 & $11.3 \%$ & & & \\
\hline
\end{tabular}




\section{Modal Test}

\section{Test results}

This section will present and discuss the experimental results gathered from all tests carried out during this investigation.

\section{Wing}

All identified modes were analyzed for their respective mode shapes. The wing symmetric and anti-symmetric model results were determined from the tips vertical excitation location. The antisymmetric wing bending mode is presented in figure (7). The mode shape definition is good, although the frequency is relatively high, the mode shape fitting proceeded. The third wing bending mode in spanwise, is presented in Fig. (8). An apparent torsion was detected within this mode, besides symmetric bending in chordwise of mid-part (fuselage location). Table (3) summarize frequencies resulted from random test.

On performing the sine tests, all identified modes were analyzed for their respective mode shapes. The test was conducted for six times. Table (4) summarizes the structural modes identified within this test.

Table.3. Results from random test

\begin{tabular}{|c|c|c|c|c|}
\hline \multicolumn{5}{|c|}{ wing modal test (random 0 -200 Hz) } \\
\hline test\# & mode\#1 & mode\#2 & mode\#3 & mode\#4 \\
\hline R1 & 22.58 & 51.01 & 60.24 & 88.16 \\
\hline R2 & 22.54 & 51.99 & 60.64 & 86.42 \\
\hline R3 & 22.58 & 51.086 & 61.757 & 84.55 \\
\hline R4 & 22.52 & & 61.16 & 88.01 \\
\hline R5 & 22.52 & & 60.77 & 87.03 \\
\hline R6 & 22.49 & & 59.69 & \\
\hline R7 & 22.48 & 52.32 & 61.04 & 79.27 \\
\hline R8 & 22.51 & 51.08 & 61.75 & 87.4 \\
\hline R9 & 22.49 & 51.99 & 60.63 & 87.41 \\
\hline
\end{tabular}

Table.4. Results from sine test

\begin{tabular}{|c|c|c|c|c|}
\hline \multicolumn{5}{|c|}{ wing modal test (sine 0 -100Hz) } \\
\hline test\# & mode\#1 & Mode\#2 & mode\#3 & mode\#4 \\
\hline s1 & 18.26 & 54.57 & & 89.35 \\
\hline s2 & 18.28 & 54.59 & 61.13 & 89.36 \\
\hline s3 & 18.65 & 54.56 & 60.98 & 90.25 \\
\hline s4 & 22.43 & 54.16 & 61.29 & 90.61 \\
\hline s5 & 22.9 & 54.32 & 61.36 & 89.63 \\
\hline s6 & 18.29 & 54.89 & & 90.58 \\
\hline
\end{tabular}

A detailed finite element model of the wing was developed on MSC/NASTRAN. The obtained results are shown in tables (5-6). 
Table 5. Results obtained from the three tests

\begin{tabular}{|c|c|c|c|}
\hline $\begin{array}{c}\text { Mode } \\
\#\end{array}$ & \multicolumn{3}{|c|}{ Frequency (Hz) } \\
\cline { 2 - 4 } & Random & Sine & F.E.M \\
\hline 1 & 22.52 & 19.80 & 20.24 \\
\hline 2 & 51.58 & 54.52 & 50.68 \\
\hline 3 & 60.85 & 61.19 & 71.93 \\
\hline 4 & 86.03 & 89.96 & 102.4 \\
\hline
\end{tabular}

Table 6. Error estimation between F.E.M, random, and sine results

\begin{tabular}{|c|c|c|}
\hline Mode\# & \multicolumn{2}{|c|}{ Error \% } \\
\hline & $\begin{array}{c}\text { Random \& } \\
\text { F.E.M }\end{array}$ & $\begin{array}{c}\text { Sine } \\
\text { \&F.E.M }\end{array}$ \\
\hline 1 & -11.28 & 2.17 \\
\hline 2 & -1.77 & -7.57 \\
\hline 3 & 15.40 & 14.93 \\
\hline 4 & 15.98 & 12.14 \\
\hline
\end{tabular}

\section{The whole frame of SAHM UAV}

Two modes were extracted when exciting at wing tips, which was the wing first twist and wing anti-symmetric twist. Also two modes were defined when exciting the airframe at the nose. The first mode involved the wing second symmetrical bending in spanwise, wing first symmetrical bending chordwise and the fuselage and vertical tail first bending, while the second mode comprised the antisymmetric bending of the fuselage. Four modes were detected during vertical tail excitation. The first bending in spanwise and chordwise was appeared. Also appeared here was the first twist of the fuselage, the anti-symmetric bending in spanwise (wing), the first fuselage and vertical tail twist modes. The wing symmetric bending in chordwise, was well defined by this excitation. Tables (7-8), summarize all modes extracted when testing the whole frame of the SAHM UAV. Fig. (9 -10) show two samples of extracted modes.

\section{Statistical Analysis}

Linear regression was performed on wing data, as see in Figs (11) and (12). Considering the whole frame of the UAV, one way ANOVA (analysis of variance) is performed on each extracted mode from both types of tests which are repeated for several times. Tables $(9-10)$, show samples of results obtained when applying ANOVA to the first two modes. This analysis provide a test of the null hypothesis, $\mathrm{HO}$, that each sample is drawn from the same underlying probability distribution against the alternative hypothesis, $\mathrm{H} 1$, that underlying probability distributions are not the same for all samples. That hypothesis can be restated in the physical terminologies of the current study to be:

HO: different treatments don't affect the calculated values of the natural modes.

$\mathrm{H} 1$ : different treatments affect the calculated values of the natural modes.

Some parameters in the ANOVA analysis could be defined in the appendix. The analysis is performed, for alpha $=0.05$, and gives the results shown in tables (9-10). Table (11) indicates the comparison between random and sine tests based on the 
practical importance. The difference between the two methods is clear as seen in column 4.

Table 7. Results obtained from random test

\begin{tabular}{|c|c|c|c|c|c|c|c|c|}
\hline \multicolumn{10}{|c|}{ AIRFRAME MODAL TEST (Random 0-200 Hz) } \\
\hline test\# & $\begin{array}{c}\text { Mode\#1 } \\
\text { (V.T) }\end{array}$ & $\begin{array}{c}\text { Mode\#2 } \\
\text { (V.T) }\end{array}$ & $\begin{array}{c}\text { Mode\#3 } \\
\text { (TIP) }\end{array}$ & $\begin{array}{c}\text { Mode\#4 } \\
\text { (NOSE) }\end{array}$ & $\begin{array}{c}\text { Mode\#5 } \\
\text { (V.T) }\end{array}$ & $\begin{array}{c}\text { Mode\#6 } \\
\text { (NOSE) }\end{array}$ & $\begin{array}{c}\text { Mode\#7 } \\
\text { V.T) }\end{array}$ & $\begin{array}{c}\text { Mode\#8 } \\
\text { (TIP) }\end{array}$ \\
\hline R1 & 22.58 & 37.26 & 40.23 & 52.60 & 66.75 & 79.90 & 90.84 & 104.48 \\
\hline R2 & 22.54 & 37.31 & 41.10 & 52.70 & 66.60 & 79.80 & 90.87 & 105.05 \\
\hline R3 & 22.58 & 37.55 & 40.78 & 52.60 & 66.70 & 79.80 & 90.80 & 104.03 \\
\hline R4 & 22.52 & 37.40 & 40.68 & 52.30 & 66.62 & 79.90 & 90.80 & 104.26 \\
\hline R5 & 22.52 & 37.38 & 40.64 & 52.20 & 66.73 & 79.90 & 90.77 & 104.17 \\
\hline R6 & 22.49 & 37.35 & 40.60 & 52.20 & 66.42 & 79.90 & 90.77 & 103.89 \\
\hline R7 & 22.48 & 37.30 & 40.68 & 52.20 & 66.66 & 79.90 & 90.80 & 103.84 \\
\hline R8 & 22.51 & 37.48 & 40.40 & 52.30 & 66.53 & 79.90 & 90.77 & 103.39 \\
\hline R9 & 22.49 & 37.40 & 40.55 & 52.30 & 66.52 & 80.00 & 90.77 & 103.66 \\
\hline R10 & 22.48 & 37.48 & 40.46 & 52.30 & 66.55 & 80.30 & 90.81 & 103.44 \\
\hline
\end{tabular}

Table 8. Results obtained from sine test

\begin{tabular}{|c|c|c|c|c|c|c|c|c|}
\hline \multicolumn{1}{|c|}{ AIRFRAME MODAL TEST (Sine 0-100Hz) } \\
\hline test\# & $\begin{array}{c}\text { Mode\#1 } \\
(\mathrm{V} . \mathrm{T})\end{array}$ & $\begin{array}{c}\text { Mode\#2 } \\
(\mathrm{V} . \mathrm{T})\end{array}$ & $\begin{array}{c}\text { Mode\#3 } \\
\text { (TIP) }\end{array}$ & $\begin{array}{c}\text { Mode\#4 } \\
(\mathrm{NOSE})\end{array}$ & $\begin{array}{c}\text { Mode\#5 } \\
(\mathrm{V} . \mathrm{T})\end{array}$ & $\begin{array}{c}\text { Mode\#6 } \\
(\mathrm{NOSE})\end{array}$ & $\begin{array}{c}\text { Mode\#7 } \\
(\mathrm{V} . \mathrm{T})\end{array}$ & $\begin{array}{c}\text { Mode\#8 } \\
(\mathrm{TIP})\end{array}$ \\
\hline S1 & 22.09 & 37.69 & 41.02 & 52.98 & 68.21 & 80.49 & 91.54 & 96.72 \\
\hline S2 & 22.17 & 37.82 & 40.78 & 53.02 & 68.34 & 80.57 & 91.49 & 94.26 \\
\hline S3 & 22.18 & 37.81 & 41.15 & 53.05 & 68.01 & 80.94 & 91.48 & 95.92 \\
\hline S4 & 22.18 & 37.81 & 41.30 & 53.02 & 68.24 & 80.62 & 91.79 & 97.73 \\
\hline S5 & 22.14 & 37.88 & 43.26 & 53.05 & 68.01 & 80.52 & 91.44 & 96.43 \\
\hline S6 & 22.27 & 37.83 & 41.25 & 53.23 & 67.99 & 80.64 & 91.62 & 99.40 \\
\hline S7 & 22.22 & 37.96 & 41.33 & 53.13 & 67.93 & 80.58 & 91.6 & 94.24 \\
\hline S8 & 22.30 & 37.78 & 41.68 & 53.07 & 67.96 & 80.55 & 91.43 & 98.01 \\
\hline S9 & 22.24 & 37.76 & 43.08 & 53.23 & 68.01 & 80.46 & 91.63 & 94.03 \\
\hline S10 & 22.20 & 37.73 & 40.87 & 53.01 & 68.17 & 80.67 & 91.56 & 96.13 \\
\hline
\end{tabular}


Table 9. One-way ANOVA: first mode

Anova: Single

Factor

SUMMARY

\begin{tabular}{ccccccc}
\hline Groups & Count & Sum & Average Variance & \\
\cline { 1 - 5 } Random Test & 10 & 225.19 & 22.519 & 0.00141 & \\
Sine Test & 10 & 221.99 & 22.199 & 0.00381 & & \\
\hline ANOVA & & & & & \\
\hline Source of Variation & SS & $d f$ & $M S$ & $F$ & $P$-value & $F$ crit \\
\hline Between Groups & 0.512 & 1 & 0.512 & $196.16864 .04 \mathrm{E}-114.413873$ \\
Within Groups & 0.04698 & 18 & 0.00261 & & \\
Total & 0.55898 & 19 & & & \\
\cline { 1 - 4 }
\end{tabular}

Table 10. One-way ANOVA: second mode

Anova: Single

Factor

SUMMARY

\begin{tabular}{|c|c|c|c|c|c|}
\hline Groups & Count & Sum & Average & Variance & \\
\hline Random Test & 10 & 373.91 & 37.391 & 0.008343 & \\
\hline Sine Test & 10 & 378.07 & 37.807 & 0.005779 & \\
\hline \multicolumn{6}{|l|}{ ANOVA } \\
\hline Source of Variation & SS & $d f$ & $M S$ & $F$ & $P$-value \\
\hline Between Groups & 0.86528 & 1 & 0.86528 & 122.5416 & 1.83E-094.413873 \\
\hline Within Groups & 0.1271 & 18 & 0.007061 & & \\
\hline Total & 0.99238 & 19 & & & \\
\hline
\end{tabular}

Table 11. The SAHM UAV modal test: comparison between random and sine tests based on the practical importance

\begin{tabular}{|c|c|c|c|}
\hline Mode \# & \multicolumn{2}{|c|}{ Frequency $(\mathrm{HZ})$} & Difference\% \\
\hline & Random & Sine & delta=Abs[(S-R)/S]\% \\
\hline 1 & 22.52 & 22.20 & 1.44 \\
\hline 2 & 37.39 & 37.81 & 1.10 \\
\hline 3 & 40.61 & 41.57 & 2.31 \\
\hline 4 & 52.37 & 53.08 & 1.34 \\
\hline 5 & 66.61 & 68.09 & 2.17 \\
\hline 6 & 79.93 & 80.60 & 0.84 \\
\hline 7 & 90.80 & 91.56 & 0.83 \\
\hline 8 & 104.02 & 96.29 & 8.03 \\
\hline
\end{tabular}


A linear regression is done. The result is shown in fig (13). The correlation coefficient $\left(R^{2}=0.9895\right)$, gives us a measure of the reliability of the linear relationship between the random test and sine test values. (Values close to one indicate excellent linear reliability).

\section{CONCLUSIONS AND RECOMMENDATIONS FOR FUTURE WORK}

Various conclusions and recommendation can be drawn based on the study performed on the SAHM UAV. These will be summarized below:

1. The MDO of the SAHM UAV was successfully performed using gradient-based algorithm with penalty operator. The gradient based algorithm converges to a solution fairly quickly and could be used efficiently as a powerful tool for obtaining high quality approximation in real-life design optimization.

2. The Multidisciplinary Design Optimization algorithm appears to be quite successful in obtaining a reduced weight air-vehicle candidates rather than designing new configurations, (Weight reduction of about $11 \%$ or greater for the whole airframe is possible at the SAHM UAV full scale).

3. Finite element analysis and design of experiment have been successfully conducted to validate the results obtained theoretically. The physical parameters of the structure have been extracted and analyzed. So we proved that we can numerically analyze, and design perfect experiments that capable to measure these parameters within a certain level of confidence.

4. Optimization setup should be expanded to include additional structural parameters as design variables or constrains. It was observed in this study that the structural results, obtained during this process, tended to be ineffective in these phase of design, and indicate a more flexible wing structure. A better formulation tailored for the SAHM UAV is required to accurately incorporate this discipline in the phase of the detailed design.

5. One area that still needed further attention was the field of UAV. The present research attempts to lie some of groundwork for a truly combined MDO-UAV environment design procedure, although it realized that this effort can merely regarded as a step in that direction. So far design procedure is still biased toward the side of some major disciplines, since that is the origin of the effort. But it can be viewed as a basis for fully integrated disciplines.

\section{REFERENCES}

[1] Emilio Frazzoli. "Robust Hybrid Control for Autonomous Vehicle Motion Planning". PhD thesis, Massachusetts Institute of Technology, (1994).

[2] Shawn E. Gano , and John E.Renaud," Optimized Unmanned Aerial Vehicle with wing morphing for extended range and endurance", AIAA-2002-5668,(2002). 
[3] Andre C.Marta,"parametric study of genetic algorithm using aircraft design optimixzation problem",Dept. of aeronautics and astronautics, Stanford university. (not available)

[4] Andy, Ko, and Leifur,T. Leifsson, "MDO of a blended-wing-body transport aircraft with distributed propulsion', multidisciplinary analysis and design center for advanced vehicles, Virginia polytechnic institute and state university, AIAA,(not available).

[5] Daniel P. Raymer, "Aircraft design: A conceptual approach", AIAA-Education Series, third edition,(1999).

[6] Richard L. Fox,"optimization methods for engineering design", Addison-Wesley publishing company.,(1971).

[7] Vanderplaats, Garret N, Numerical Optimization Techniques for Engineering Design, Vanderplaats Research \& Development, Inc, (2001).

[8] Michael T. Heath,"Scientific Computing An Introductory Survey - Optimization" Second Edition, (2001).

[9] Joines, J and Houck, C., "On the Use of Non-Stationary Penalty Functions to Solve Nonlinear Constrained Optimization Problems with GA's". Proceedings of first IEEE Conference on Evolutionary Computation, pp. 579-584, (1994).

[10] Dr. Jan Roskam,"Airplane Design I-VII", DarCorporation, first printing, (1997).

[11] John D. Anderson, Jr.,"Aircraft performance and design", International edition, McGraw-Hill Companies. Inc.,(1999).

[12] Hewlett Packard," Fundamentals of Signal Analysis", Application Note243,(1991).

[13] Ewins D.J.,"Modal Testing:Theory,Practice and Application", Second Edition.Resaerch Studies Press LTD., Baldock. Hertfordshire. Enqland.(2000).

4. Cruise to target

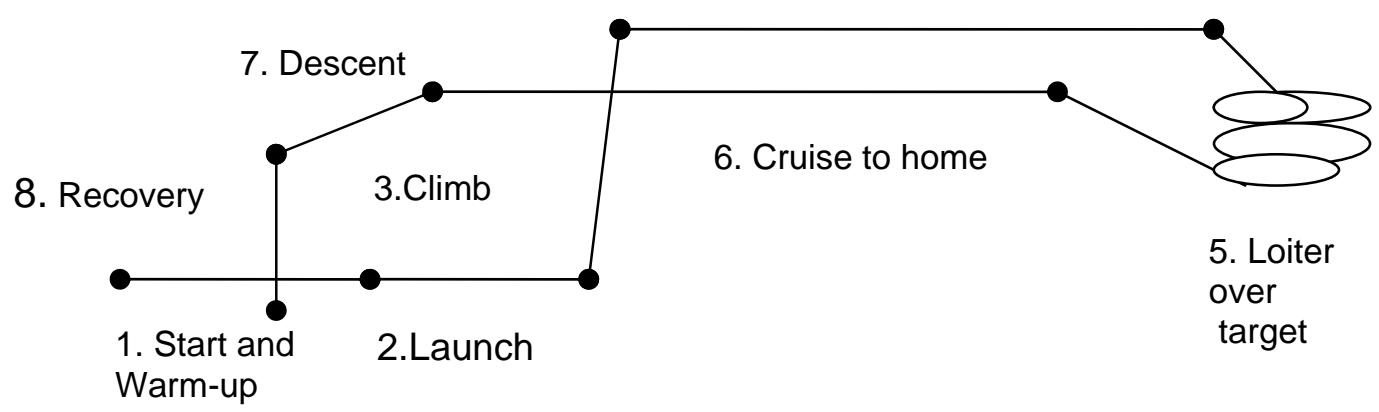

Fig.1. Mission profile 

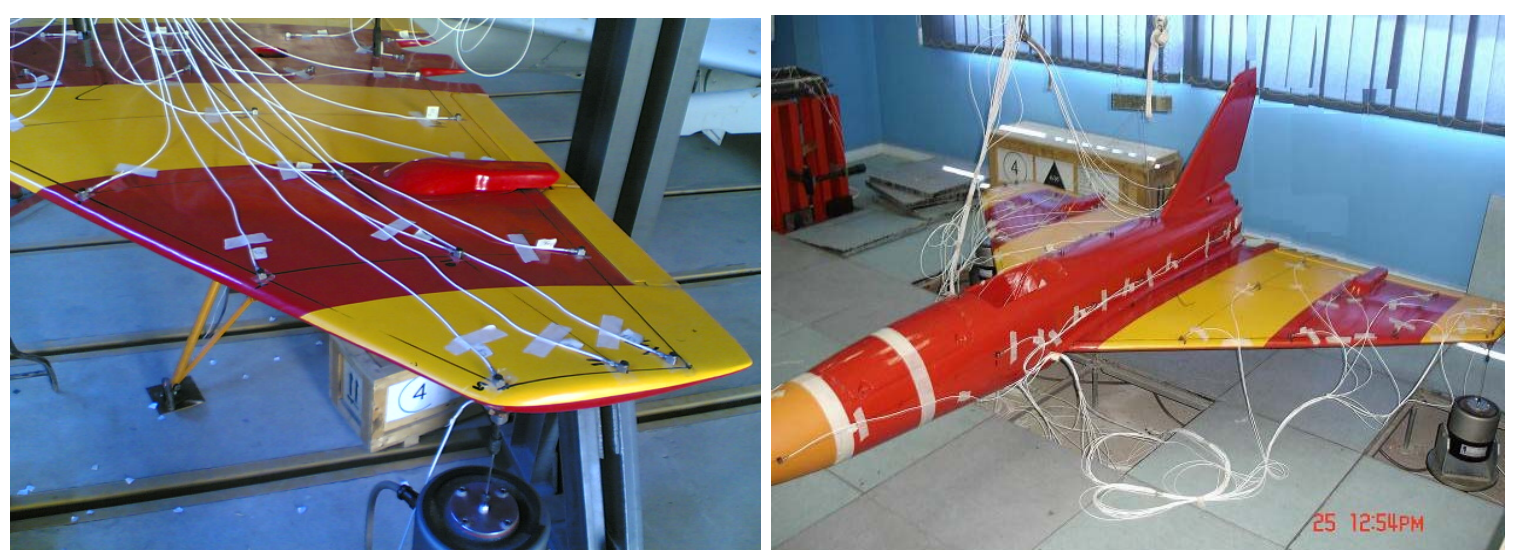

Fig.2. Measurement locations on wing Fig.3. Measurement locations on airfarme

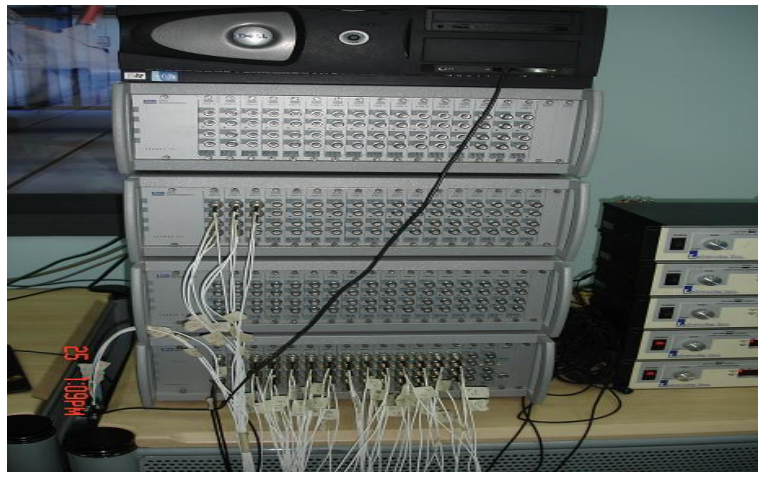

Fig.4. The LMS DIFA III system

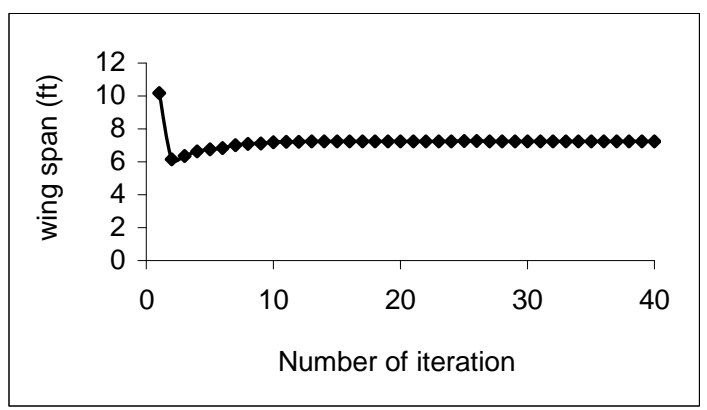

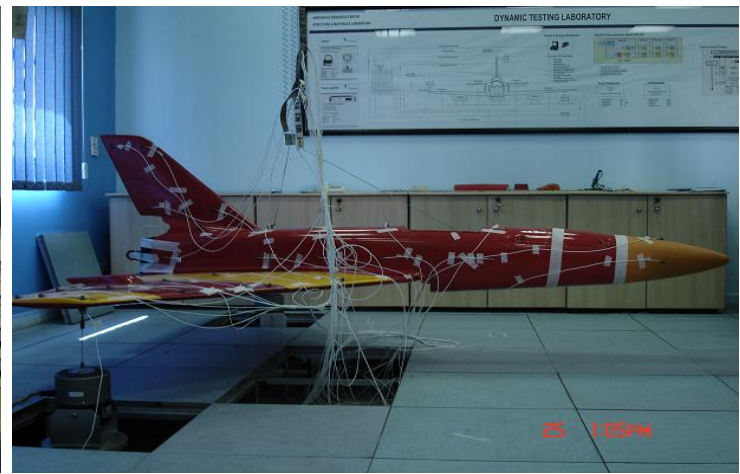

Fig.5.SAHM UAV softly suspended on air-cables

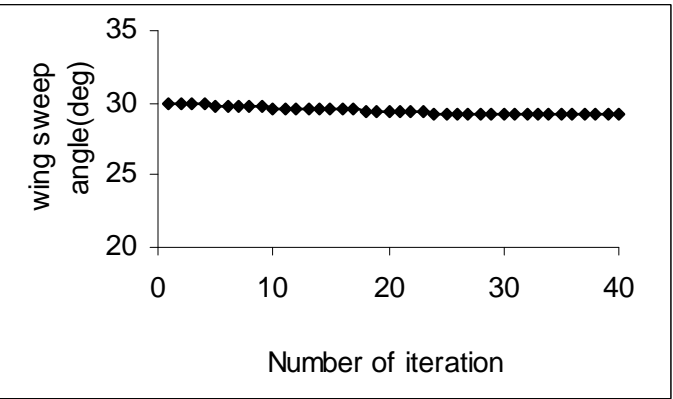



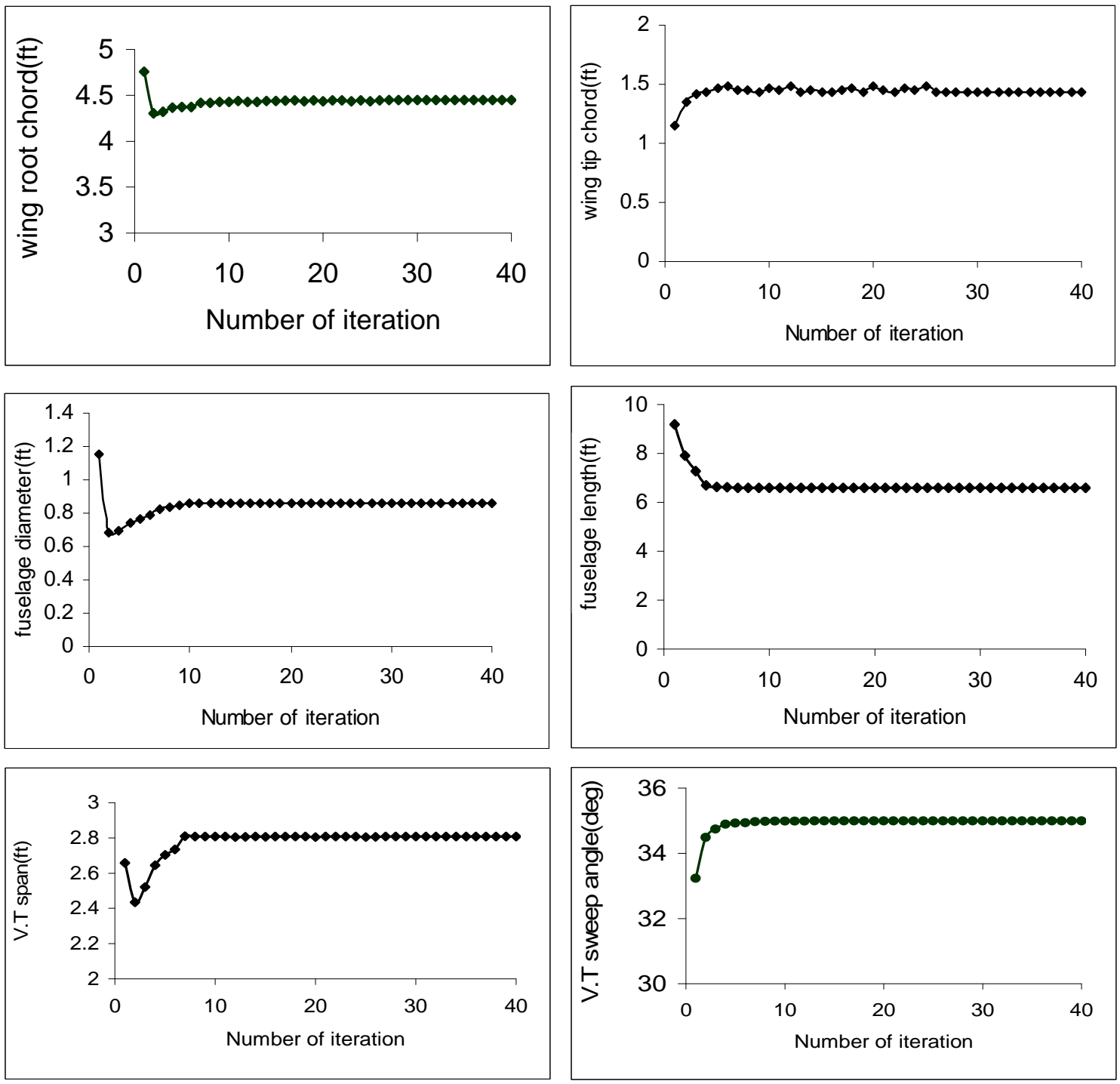

Fig.6. convergence history from baseline configuration to the optimum configuration
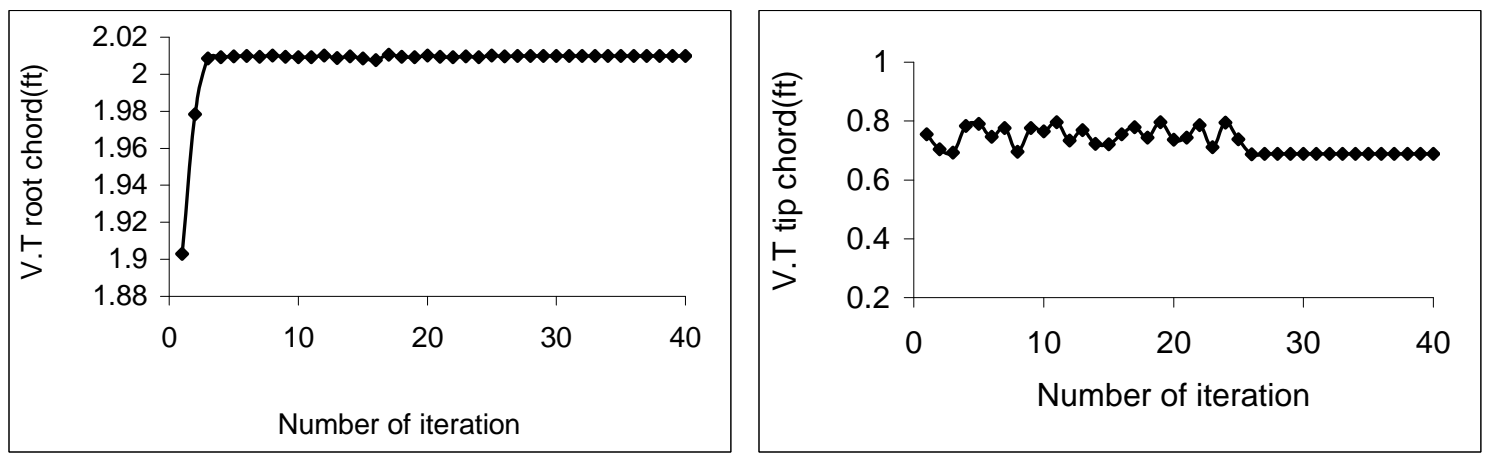

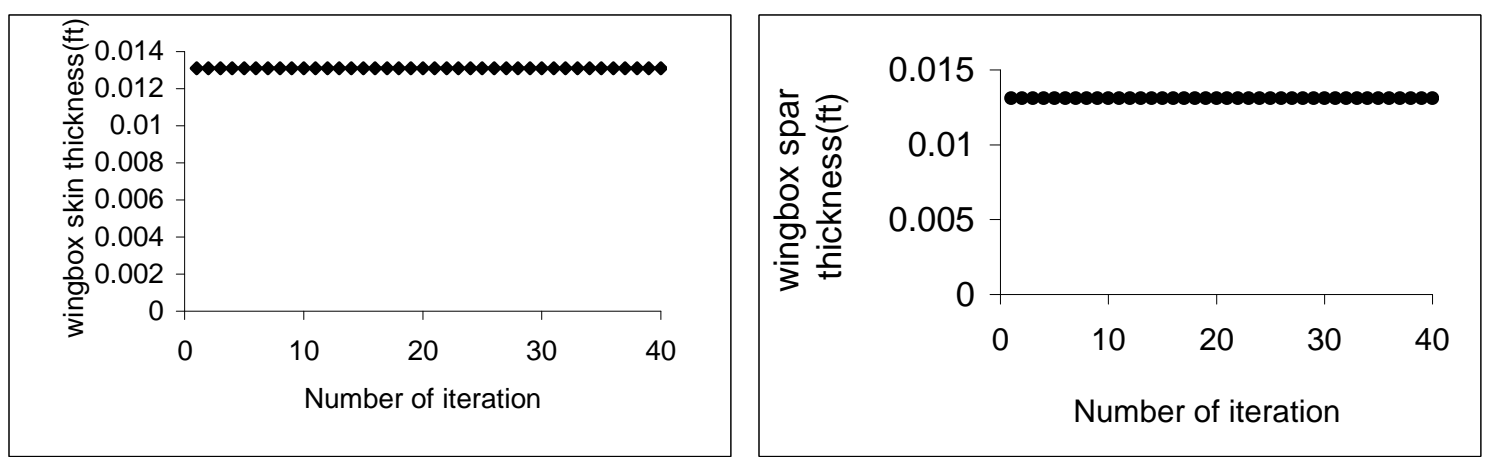

Fig.6. (Continued)

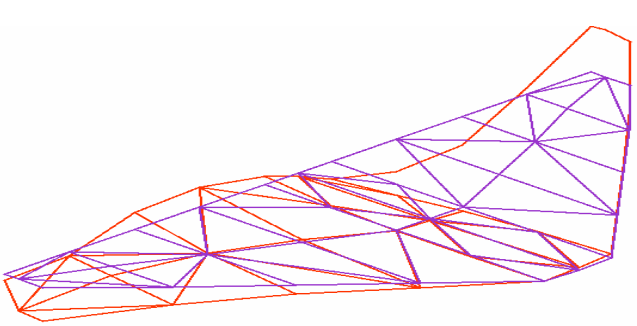

Fig. 7 The antisymmetric wing bending mode: $(64.06 \mathrm{~Hz})$

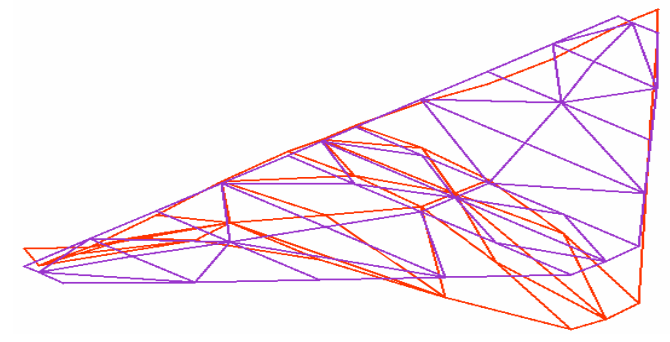

Fig. 8 The third wing bending mode :(90.25 Hz).

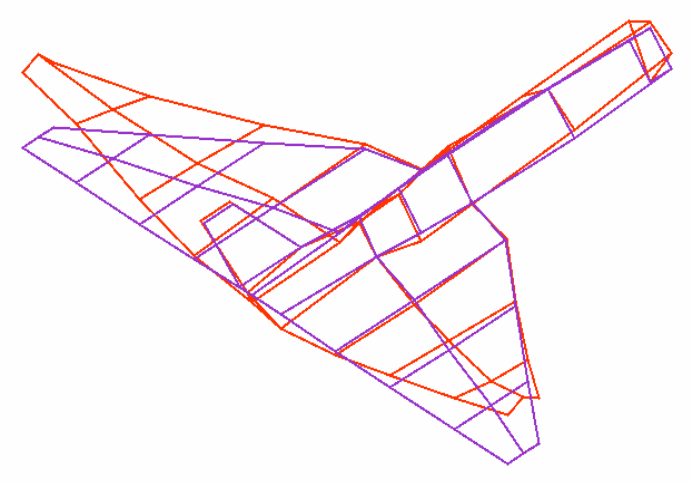

Fig. 9 Mode\#1: 22.58 Hz (V.T)

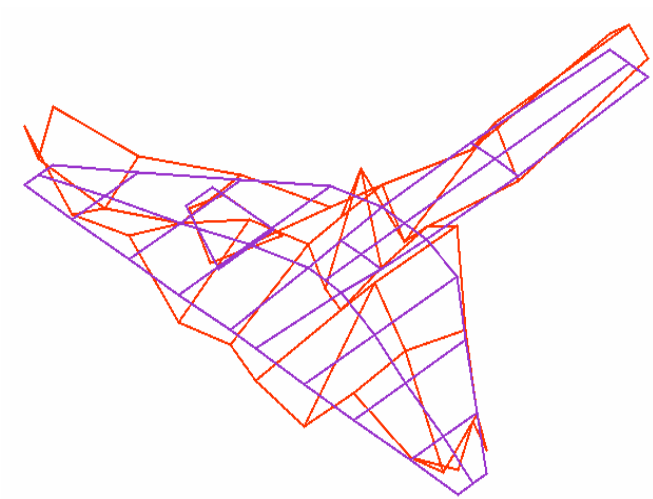

Fig. 10 Mode\#2: $37.69 \mathrm{~Hz}$ (V.T) 


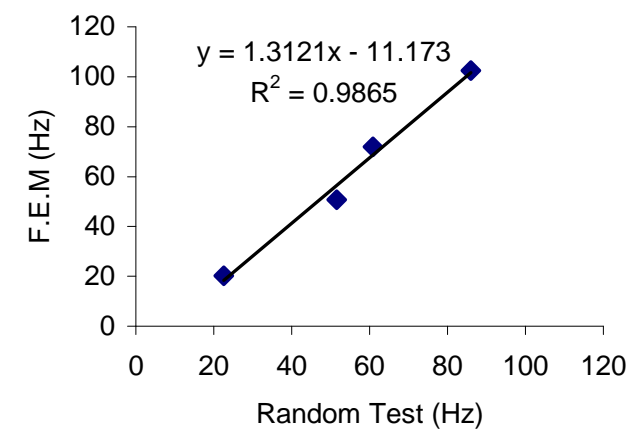

Fig.11. Correlation between F.E.M and random test

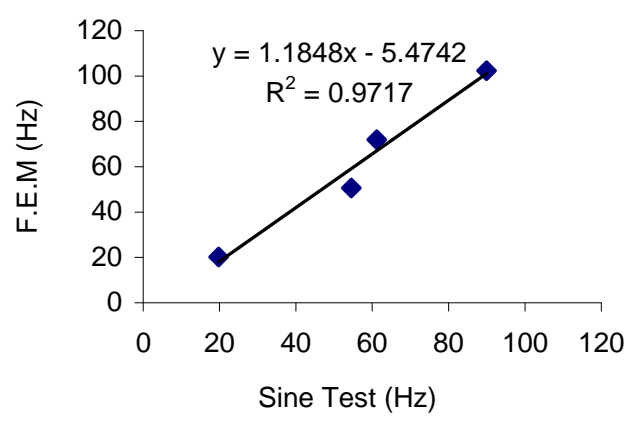

Fig.12. Correlation between

F.EM.and sine test

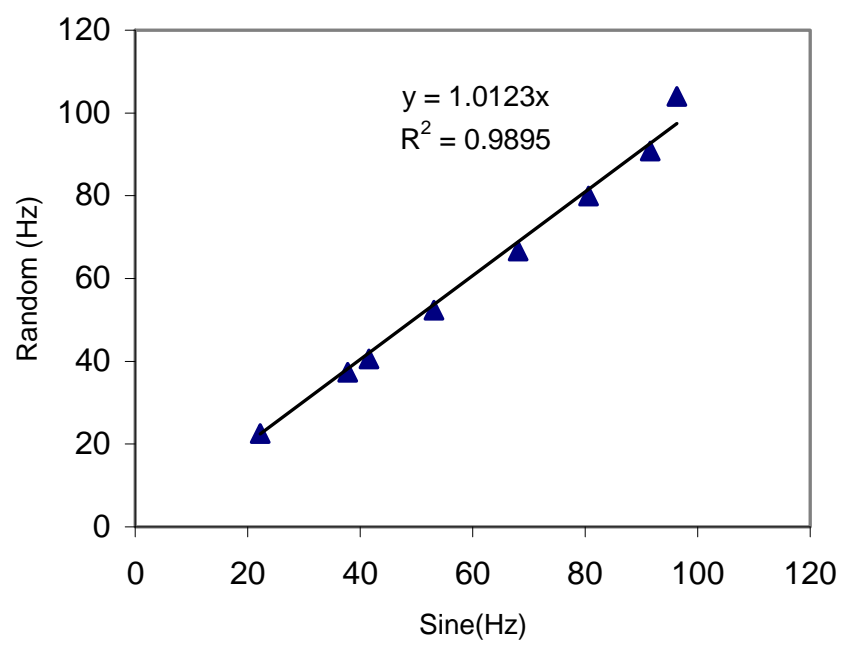

Fig.13. Correlation between Random and Sine tests based on linear regression 


\section{APPENDIX}

Definition of some parameters used in the ANOVA analysis.

$$
\begin{aligned}
& \mathrm{SS}_{\text {total }}=\mathrm{SS}_{\text {treatment }}+\mathrm{SS}_{\mathrm{E}} \\
& \mathrm{df}_{\text {total }}=\mathrm{df}_{\text {tratment }}+\mathrm{df}_{\mathrm{E}} \\
& \mathrm{df}_{\text {tratment }}=\mathrm{a}-1 \\
& \mathrm{df}_{\mathrm{E}}=\mathrm{a}(\mathrm{n}-1) \\
& \mathrm{MS}_{\text {treatment }}=\mathrm{SS}_{\text {treatment }} / \mathrm{df}_{\text {tratment }} \\
& \mathrm{MS}_{\mathrm{E}}=\mathrm{SS}_{\mathrm{E}} / \mathrm{df}_{\mathrm{E}} \\
& \mathrm{F}_{\text {statistic }}=\mathrm{MS}_{\text {treatment }} / \mathrm{MS}_{\mathrm{E}}
\end{aligned}
$$

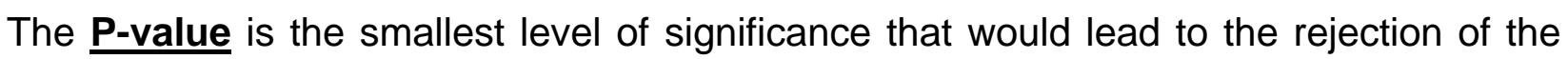
null hypothesis $\mathrm{HO}$ with the given data.

Alpha: is the level at which we want to evaluate critical values for F-static.

The Alpha level is a significance level related to the probability of having a type I error (rejecting a true hypothesis) 